\title{
Analysis of BYD's Business Model and Future Development Prospects
}

\author{
Yundi $\mathrm{Gao}^{1, *}$ \\ ${ }^{1}$ Business School, The University of Edinburgh, EH8 9JS, Edinburgh, United Kingdom
${ }^{*}$ Corresponding author. Email: s1944606@ed.ac.uk
}

\begin{abstract}
This paper uses PEST analysis and SWOT analysis to explore the macro environment and development prospects of BYD in the Chinese market. The study found that BYD has clear advantages in terms of price and business scope, but technological innovation and sales channels are areas that BYD needs to focus on and improve promptly. In addition, the favourable policies for the new energy industry introduced by China in recent years indicate that the macro environment of China at this time is very conducive to BYD's future growth. BYD's outstanding strengths and the environment in which it operates indicate that it has a very bright future. Exploring the future of BYD will not only give the public a clearer picture of the company, but can also be used as a reference for investors to help them make further decisions. More importantly, BYD is the industry benchmark for new energy vehicle companies in China. The study of BYD's future development direction can also provide some guidance and reference to the study of the development of China's new energy and automotive industries.
\end{abstract}

Keywords: BYD, SWOT analysis, PEST analysis, company development prospect.

\section{INTRODUCTION}

As the largest developing country, China's economy has gained momentum in recent years, with GDP reaching RMB 2,493.1 billion in the first quarter of 2021, up $18.3 \%$ year-on-year. Against the backdrop of a Chinese economy that is expected to continue to reach new heights, industry insiders are optimistic about the prospect of China's development. In this context, China is paying more and more attention to the development of new energy vehicles, as evidenced by the gradual strengthening of environmental policies and the introduction of a carbon-neutral perspective in recent years. As a result, new energy vehicles have gradually become the future trend of development of China's automotive industry, and more and more traditional Chinese car companies have begun to transform themselves from the traditional fuel car market to the new energy vehicle market.

Among them, BYD Co. Ltd. (BYD) can be called the representative enterprise of these transforming car enterprises. In addition, BYD's research and development in blade batteries have helped it dominate the Chinese new energy vehicle market. At present, the main listed companies in China's new energy vehicle industry include BYD, GAC Group, Geely and Changan Automobile, and so on. According to the sales volume of Chinese energy vehicle companies in 2020, BYD achieved 183,200 units of sales, becoming the company with the highest sales volume of new energy vehicles in China. Meanwhile, BYD is ranked third among the top 10 global new energy vehicle sellers in 2020 by EV Sales. With such outstanding results, BYD makes one wonder what its future trends and prospects will be.

This paper focuses on BYD's current business situation, analyses its strengths, weaknesses, potential risks and opportunities through the SWOT and PEST models, and finally predicts the prospect of BYD's development. SWOT analysis is a widely used tool to provide a systematic approach and support for decisionmaking situations and to analyse the internal and external environment. It analyses an organization's S (Strengths), $\mathrm{W}$ (Weaknesses), O (Opportunities), and T (Threats) by integrating and generalizing internal and external conditions to provide a basis for strategic planning [1-3]. Kotler suggests that external factors can be classified according to their attractiveness and likelihood of success, i.e., opportunities, and severity and the likelihood of occurrence, i.e., threats. Internal factors can be defined in a hierarchy based on their performance and importance [4]. Weihrich proposed the TOWS matrix in 
1982 [5]. The purpose of this matrix is to identify the relationship between strengths, weaknesses, opportunities, and threats. In addition, Weihrich also worked out a structure for generating strategies based on these relationships [5]. PEST analysis refers to the analysis of the macro-environment in which a company operates, usually through the four factors $\mathrm{P}$ (political), E (environmental), $\mathrm{S}$ (social), and $\mathrm{T}$ (technological), to analyse the situation faced by the company [6]. The economic aspects include the level of economic development, growth rates, government revenues and expenditures, inflation rates, and so on [7-9]. The political aspect includes the political system, government policies, national industrial policies, relevant laws, and regulations, etc. [10]. Social aspects include population, values, moral level, etc. The technological aspect contains breakthroughs in high technology.

The remainder of the article is organized as follows. The second part of the paper will introduce BYD's company profile, including its corporate development, main businesses, and key events. The third and fourth parts of the paper will analyse BYD's strengths and weaknesses, its environment, and the risks and opportunities it is likely to face in the future, using the SWOT and PEST models, respectively. The fifth section will further analyse the prospects of BYD on this basis and make constructive suggestions for BYD's future development. The final part of the paper will summarize the previous analysis, highlight the paper's shortcomings, and propose future research plans.

\section{FIRM DESCRIPTION}

BYD was founded in 1995 and has four major industries - IT, new energy, automotive, and rail transportation. The company employs more than 220,000 people, with approximately 23,000 R\&D staff, and has a turnover and market capitalization of over RMB100 billion. According to BYD's official website, the automotive business is the company's core business, accounting for $53.64 \%$ of revenue in 2020 . To date, the company has launched over 50 models, with sales reaching a peak of 520,000 units in 2018. Due to the gradual increase in market competition, BYD's sales of conventional fuel vehicles have been on a general downward trend from 2014-2019, with a gradual decline in market share. In contrast, BYD's new energy vehicle sales experienced rapid growth during 2015-2018. This shows that the new energy vehicle is the main direction of the Company's future strategic development.

The electronics business is the company's secondlargest business, involving machine design, component production and machine assembly services. BYD has the capacity to manufacture and assemble much hardware such as batteries, housings, keyboards, etc. The scale of this business continues to expand. The battery business is the company's third-largest business. BYD has independently developed mainstream power battery technologies such as lithium iron phosphate and ternary lithium batteries, which are widely used in mobile phones, electric vehicles, energy storage, and other portable electronic devices. In general, the total revenue of the three businesses accounted for $99.70 \%$ of the company's general income. In addition, to meet the diversified market demand, the urban rail transportation business has also become one of BYD's future development directions.

In Figure 1, BYD's share price showed a general upward trend from September 2020 to August 2021, increasing $113.17 \%$ over the year, as shown in Figure 1. The reasons for such an impressive rise in BYD can be demonstrated in the following ways. Firstly, BYD sold 57,410 cars in July 2021, an increase of $83 \%$ year-onyear. It is worth mentioning that orders of the DM-i model exceeded 100,000 units, and there are still a large number of orders yet to be delivered. It is expected that with the release of production capacity one after another, sales of DM-i are expected to rise continuously. In addition, BYD signed an agreement with Do-fluoride New Materials, Guangdong Tonze Electric and Bicon to purchase a total of not less than 14,470 tons of lithium hexafluorophosphate, corresponding to about $90 \mathrm{GWh}$ or more of lithium iron phosphate batteries. This shows that the future shipment of the company's blade batteries is expected to exceed expectations.

\section{BYD's stock price trend}

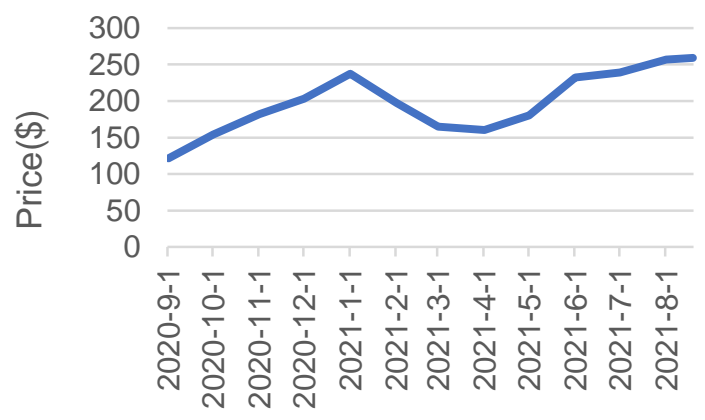

Figure 1 BYD stock price change from Sep.2020 to Aug.2021 (data source: Yahoo Finance)

\section{SWOT ANALYSIS}

SWOT analysis is a widely used tool to provide a systematic approach and support for decision-making situations and to analyse the internal and external environment. This paper will discuss BYD using a SWOT analysis to identify its strengths, weaknesses, opportunities, and threats. See table 1 for details. 
Table 1. SWOT analysis for BYD

\begin{tabular}{|ll|ll|}
\hline S & Technological & W & \\
2uperiority & 1. & $\begin{array}{l}\text { Technological } \\
\text { disadvantage }\end{array}$ \\
3. & $\begin{array}{l}\text { Price advantage } \\
\text { business }\end{array}$ & 2. & $\begin{array}{l}\text { Disadvantage of } \\
\text { distribution sales } \\
\text { method }\end{array}$ \\
4. & $\begin{array}{l}\text { Appropriate forms of } \\
\text { financing }\end{array}$ & 3. & Difficult to specialize \\
5. & $\begin{array}{l}\text { Abundant sales } \\
\text { channels }\end{array}$ & $\mathbf{T}$ & \\
\hline O & 1. & $\begin{array}{l}\text { Threats from } \\
\text { competitors }\end{array}$ \\
1. & $\begin{array}{l}\text { National favorable } \\
\text { policy }\end{array}$ & 2. & Patent disputes \\
2. & National planning & 3. & $\begin{array}{l}\text { The lack of } \\
\text { motivation }\end{array}$ \\
& & & \\
\hline
\end{tabular}

\subsection{Strength}

(1) Technological superiority. In the new energy field, BYD is fully capable of developing, designing, and producing batteries on its own. In 2020 BYD launched its own core technology, the Blade Battery. This battery can meet the demand for a range of more than 600 kilometres on a single charge and has an extremely high battery life of more than 3,000 charges/discharge cycles. In addition, its most important feature is the greatly improved safety compared with the traditional battery, which completely draws the line at spontaneous battery combustion. On 13 November 2020, BYD launched its DM-i hybrid technology with Xiaoyun engine dedicated to plug-in hybrid electric vehicles (PHEV). With a brake thermal efficiency (BTE) of $43 \%$, this new efficient $1.5 \mathrm{~L}$ plug-in hybrid engine is the most thermally efficient petrol engine globally. BYD has core technologies of its own in all areas it covers. Up to now, BYD has mastered 26,671 patented technologies, ranking first in China.

(2) Price advantage. BYD develops its own automotive batteries to provide raw materials for its automotive products in terms of cost. BYD chooses lithium iron phosphate as the power battery because it is the safest power battery and because the cost of this battery will be very low after mass production. In addition, the different models of BYD cars have a price advantage over their respective counterparts in the market, making them more cost-effective and more likely to be preferred by customers.

(3) A wide range of business. BYD's businesses are complex, including electric cars, photovoltaics, electronics foundry, and energy storage plants, and so on. BYD's electronics foundry business has a relatively stable track record, while the electric car is its core business. Such a wide range of businesses allows BYD to have a presence in different markets and allows for a richer revenue stream.

(4) Appropriate forms of financing. BYD has been continuously expanding its financing channels. In 2021 H1, BYD has completed two rounds of strategic financing for its semiconductor business, introducing a number of well-known investment institutions and industrial capital. After the two rounds of financing, the valuation of BYD's semiconductor business reached 10.2 billion yuan.

(5) Abundant sales channels. In 2008, BYD adopted the distribution method for different models and had successfully established four distribution outlets. 2010, with the rapid expansion of BYD's business, the number of outlets has increased to 1,200 [11]. The advantage of this distribution sales method lies in the fact that it can make the operation more refined and more conducive to creating brand uniqueness, thus accelerating the development of the brand. In addition, this model also helps BYD identify the market's state more accurately and quickly seize the opportunity to achieve a rapid rise in sales when the car market is in good shape.

\subsection{Weakness}

(1) Technological disadvantage. The car battery chosen by BYD (lithium iron phosphate) has technical problems such as low energy density, low conductivity, low capacitance, and a low yield. In addition, there are problems with the cars themselves. There is a significant gap between the durability and performance of BYD cars and those of well-known brands in the international market.

(2) Disadvantage of distribution sales method. BYD uses distribution as its main sales model and has developed more than 1,200 distribution outlets in 2010 . However, BYD also developed a conflict of interest with its dealers in the same year, with a large number of dealers dropping out of the outlet, resulting in a sharp decline in BYD's market sales. BYD could only adopt a strategy of significantly reducing prices to recoup its losses to attract consumers' attention in 2011 [12]. This shows that BYD's distribution model has certain disadvantages. If the model of cars is single and the product innovation cycle is long, some dealers will not be able to get good models. Then the profitability of the dealers is hardly optimistic. Under such circumstances, dealers' loyalty to the brand will decline.

(3) Difficult to specialize. In addition to the automotive business for which BYD is best known, it has also expanded into photovoltaic and energy storage power plants. However, the disadvantage of having multiple businesses is that it will be more difficult and costly to manage. More importantly, BYD has limited 
capital and energy to develop multiple businesses simultaneously, making it difficult to achieve the top level of research and development in all its businesses, which puts it at a certain disadvantage in the face of a highly specialized market competition.

\subsection{Opportunity}

(1) National favourable policy. As the new energy vehicle industry gradually explodes, China has launched a series of favourable policies to develop new energy vehicles. With new policies in place, China's new energy vehicle market is set to rise to the next level. For example, China's 12th Five-Year Plan explicitly includes the automotive industry in its development plan, and the new energy vehicle industry is included in the country's seven strategic emerging industries by the Chinese government [13]. Under the current Chinese subsidy policy, the central government and local governments can subsidize a vehicle up to a total of RMB 60,000 [13]. As a result, the cost of purchasing a new energy vehicle is already comparable to that of a regular gas-guzzling vehicle after receiving the subsidies. The introduction of these supportive policies for the new energy industry will bring unlimited opportunities for BYD.

(2) National planning. The eighth point of the "Automobile Industry Development Policy" released by China points out that China guides and encourages the development of energy-saving and environment-friendly vehicles. The automobile industry should adjust strategy and requirements for emission standards according to national energy structure and actively carry out research and industrialization of new types of power such as electric vehicles and vehicle power batteries [14]. China will take measures to promote the production and use of hybrid vehicles in terms of scientific and technological research, technological transformation, and policy environment. With the strong support of China's policy, the market for electric cars will be even hotter.

\subsection{Threat}

(1) Threats from competitors. Although BYD has occupied a place in the Chinese auto market, more and more Chinese independent brands such as Great Wall Motor have also entered the field of car production. In addition to Chinese companies, Toyota, Honda, General Motors, and other companies also have certain research and development capabilities in new energy vehicles. Under this situation, BYD's technological leadership is likely to be overtaken. In addition, BYD is also likely to face the price threat from competitors. On the one hand, competitors may reach the scale effect to reduce the unit product cost. If competitors sell products at the same price, then they can get more profit. On the other hand, if the competitors keep the same profit per unit of product, they can sell the product at a lower price to expand the market share.

(2) Patent disputes. BYD has had more than one patent dispute with Foxconn and Sony, so BYD's future development still leaves a hidden danger.

(3) The lack of innovation. BYD's ability to innovate has been under question, and the delay in launching its own innovative models has prevented it from upgrading its car class. However, China's auto market has always been flooded with new companies, such as Chery and Geely, which have started designing and manufacturing new energy vehicles. If BYD's innovation ability has not been strengthened, other companies will likely overtake it.

\section{PEST ANALYSIS}

PEST analysis refers to the analysis of the macroenvironment in which a company operates, usually through the four factors P (political), E (environmental), $\mathrm{S}$ (social), and $\mathrm{T}$ (technological), to analyse the situation faced by the company. PEST analysis can grasp the macro-environment faced by BYD in general and evaluate the impact of these factors on BYD's strategic objectives and strategy formulation. See below for details.

\subsection{Political factors}

In recent years, China has introduced favourable policies for new energy companies. For example, the Chinese government's subsidy policy encourages car owners to choose different prices and types of vehicles, which positively affects BYD's market sales. In addition, the vehicle purchase tax exemption for new energy vehicles and the new energy double points policy also express China's determination to vigorously develop the new energy industry. However, with the growing popularity of the new energy industry, China has begun to adjust its regulations on industrial pollution levels, production safety requirements, and employee rights protection, which in turn have placed some restrictions on BYD's development.

\subsection{Environmental factors}

China's GDP has reached 532,167 billion yuan in the first half of 2021, up $12.7 \%$ year-on-year, showing an overall trend of steady growth. The annual value of China's GDP and the value of the increase can show that China's economy is running well. In addition, as the largest developing country, citizens' living standards are improving day by day, and their disposable income has increased significantly. This will lead more and more people to seek a higher level of economic consumption, and automobile consumption is among them. This positive development brings a good economic 
environment for the development of BYD. It is worth noting that by the end of June 2021, China had 6.03 million new energy vehicles, accounting for about $50 \%$ of global new energy vehicle ownership. This value clearly shows how hot the new energy industry is in China.

\subsection{Social factors}

While China's economy has grown rapidly in recent years, pollution of the natural environment has become increasingly serious. As the world's largest producer and seller of cars, the air pollution caused by vehicle emissions has become widely known. In this context, China has started to tackle the problem of environmental pollution by reducing harmful emissions and calling on the public to enjoy the least environmentally damaging travel options. New energy vehicles are becoming the first choice for Chinese citizens as they require much less energy than ordinary fuel cars and can optimize the environment and save energy.

\subsection{Technological factors}

As an early entrant to the new energy market in China, BYD has slowly mastered several core technologies of electric vehicles through its own continuous innovation. Its self-developed pure electric real-time four-wheel drive technology is its winning formula in terms of electric vehicle power. In terms of electric control, BYD, as the only car company in China with a complete IGBT industry chain and mass production, has been researching and developing in this area for more than 10 years, with rich experience and technology accumulation, and the key indicators have reached the world's leading level. This strong technological R\&D capability has become the driving force and foundation for BYD's continuous development.

\section{DISCUSSION}

BYD's outstanding sales and market share are due to its diversification strategy and the macro environment conducive to developing the new energy vehicle industry. In addition to its primary automotive business, BYD is also involved in different categories of industries such as batteries and household appliances. This diversified growth model allows the company to rely on products in other areas to cover capital losses in the event of market turbulence of the main product, achieving the objective of diversifying risk [15]. In addition, diversification would allow the company to expand into multiple areas of growth. Suppose BYD can achieve different levels of success in different areas. In that case, the firm's overall performance will be enhanced, which will put it in a favorable position to compete in M \& A. However, as the Chinese automotive market gradually matures, BYD faces both opportunities and challenges in the process of development and innovation. Firstly, BYD lacks core technologies and independent innovation capabilities due to its excessive business development. The advanced technologies that BYD uses to manufacture its products are more often imported from overseas, and these imported technologies are very homogeneous and proprietary [16]. As a result, it is difficult for BYD to pursue growth in technological relevance. Secondly, BYD has continued to accelerate its growth in the automotive industry in pursuit of rapid development. However, BYD's new models have been subject to numerous complaints, and the quality of the cars has been questioned as never before. The automotive market is known for strict requirements for the business proficiency of workers. If BYD does not properly check the quality of workers' work to launch its products quickly, it will only bring down its brand image.

This paper makes the following recommendations for BYD's adjustment strategy based on the above issues. Firstly, BYD needs to put the development of its main business in the first place and use the advantages brought by its main business to develop in other areas. Obviously, the automotive business is the most profitable business for BYD at the moment. The company should invest maximum financial and human resources into it to help build brand awareness for the company. The main business can provide substantial financial assistance to the company's new business so that the research and development of new products will not be financially constrained. At the same time, the technology of the main business can also support the development of new businesses. If BYD continues to upgrade and develop independent automotive production technologies (e.g., automotive powertrain, automotive battery, etc.), these technologies can also serve to support other businesses, such as rechargeable batteries, electronics foundry, etc. Secondly, BYD needs to strengthen its R\&D efforts. To gain a foothold in the international market, BYD must strengthen its own R\&D capabilities as soon as possible, master its unique core technologies and manufacturing capabilities, and gradually break away from its dependence on foreign technologies. Thirdly, BYD can make strategic alliances with its competitors as appropriate. Excessive competition with companies in the same industry will often lead to a lose-lose situation. BYD can cooperate with its competitors in areas such as technology to achieve resource sharing and technological innovation and achieve a win-win situation. Finally, when BYD has reached a stage where it needs to expand its business, it can choose to merge with or acquire smaller companies. The M\&A strategy can effectively help BYD broaden its sales channels and market share, thus enhancing the market competitiveness of BYD. 


\section{CONCLUSION}

This paper uses PEST analysis and SWOT analysis to explore the macro environment and development prospects of BYD in the Chinese market. SWOT analysis can effectively identify a company's strengths and weaknesses and help it to exploit opportunities and avoid threats. In contrast, PEST analysis can comprehensively analyse the impact of a company's internal and external environment on its strategy and help it to achieve the best fit with the internal and external environment. The study found that BYD has clear advantages in terms of price and business scope, but technological innovation and sales methods are areas that BYD needs to focus on and improve in a timely manner. In the face of fierce competition from well-known international brands, BYD needs to improve its in-house research and development capabilities as soon as possible to maintain its brand position. As BYD's main market, economic development and many policies of China are in line with the development direction of BYD. To address the issue of environmental pollution, China has introduced energysaving and emission policies in recent years and raised the subsidy standards for new energy vehicles, all signs of China's encouragement of the development of the new energy industry. BYD should seize this opportunity to capitalize on its strengths to rapidly develop the market for the brand and develop new industries while its main business takes hold. Overall, BYD is now in a macro environment that is well suited to its direction of development. BYD's future prospects are boundless as long as it keeps pace with these favourable policies and knows how to adjust to changes in the macroenvironment.

Although this paper has drawn basic conclusions about BYD's future prospects, the research process lacks data to justify the conclusions, resulting in a lack of specificity. To further arrive at more accurate results, a more in-depth analysis of BYD's historical financial position and share price movements could be conducted in the future as a means of predicting BYD's growth.

\section{REFERENCES}

[1] Pickton, D. W., \& Wright, S. (1998). What's swot in strategic analysis?. Strategic change, 7(2), 101-109.

[2] Houben, G., Lenie, K., \& Vanhoof, K. (1999). A knowledge-based SWOT-analysis system as an instrument for strategic planning in small and medium sized enterprises. Decision support systems, 26(2), 125-135.

[3] Jackson, S. E., Joshi, A., \& Erhardt, N. L. (2003). Recent research on team and organizational diversity: SWOT analysis and implications. Journal of management, 29(6), 801-830.
[4] Kotler, P., \& Turner, R. E. (1997). Marketing management: Analysis, planning, implementation, and control (Vol. 9). Upper Saddle River, NJ: Prentice hall.

[5] Weihrich, H. (1982). The TOWS matrix - A tool for situational analysis. Long range planning, 15(2), 5466.

[6] Sammut-Bonnici, T., \& Galea, D. (2014). PEST analysis.

[7] Ho, J. K. K. (2014). Formulation of a systemic PEST analysis for strategic analysis. European academic research, 2(5), 6478-6492.

[8] Peng, G. C. A., \& Nunes, M. B. (2007, July). Using PEST analysis as a tool for refining and focusing contexts for information systems research. In 6th European conference on research methodology for business and management studies, Lisbon, Portugal (pp. 229-236).

[9] Koumparoulis, D. N. (2013). PEST Analysis: The case of E-shop. International Journal of Economy, Management and Social Sciences, 2(2), 31-36.

[10] Carruthers, H. (2009). Using PEST analysis to improve business performance. In practice, 31(1), 37-39.

[11] Fan, Z. (2011). BYD Auto: Channel Crisis and Improvement Strategy. Market Modernization, (19), 35-36.

[12] Tang, L. \& Ding, B. (2010). Dealers exit the network- - BYD is in trouble on all sides. China Market, (38),36.

[13] Zhen, W. (2012). Research into Reverse Innovation - - A Case Study of BYD Company Limited. Science \& Technology Progress and Policy, (05),18-22.

[14] Chen, H. (2019). Environmental analysis of new energy vehicles based on PEST analysis - - A Case Study of BYD Company Limited. Liaoning Economy, (05),38-39.

[15] Guo, Y. (2010). A Study on the Independent Innovation Path of Local High-tech Enterprises in Foreign Capital-intensive Regions - - A Case Study of BYD Company Limited in Shenzhen. Business China (first half of the month), (05),305+304.

[16] Li, J. (2012). BYD: Technology is the most important and innovation is the foundation. China Invention \& Patent, (04),89-91. 